\title{
Glucose Tolerance and Left Ventricular Pressure-Volume Relationships in Frequently Used Mouse Strains
}

\author{
Wouter Oosterlinck, Annelies Vanderper, Willem Flameng, and Paul Herijgers \\ Division of Experimental Cardiac Surgery, Department of Cardiovascular Diseases, K.U.Leuven, 3000 Leuven, Belgium \\ Correspondence should be addressed to Paul Herijgers, paul.herijgers@med.kuleuven.be
}

Received 14 September 2010; Revised 6 December 2010; Accepted 13 December 2010

Academic Editor: Oreste Gualillo

Copyright (C) 2011 Wouter Oosterlinck et al. This is an open access article distributed under the Creative Commons Attribution License, which permits unrestricted use, distribution, and reproduction in any medium, provided the original work is properly cited.

\begin{abstract}
We investigated glucose tolerance and left ventricular contractile performance in 4 frequently used mouse strains (Swiss, C57BL/6J, DBA2, and BalbC) at 24 weeks. Glucose tolerance was tested by measuring blood glucose levels in time after intraperitoneal glucose injection $(2 \mathrm{mg} / \mathrm{g}$ body weight). Left ventricular contractility was assessed by pressure-conductance analysis. Peak glucose levels and glucose area under the curve were higher (all $P<.05)$ in C57BL/6J $(418 \pm 65 \mathrm{mg} / \mathrm{dL}$ and $813 \pm 100 \mathrm{mg} \cdot \mathrm{h} / \mathrm{dL}$ ) versus Swiss $(237 \pm 66 \mathrm{mg} / \mathrm{dL}$ and $470 \pm 126 \mathrm{mg} \cdot \mathrm{h} / \mathrm{dL})$, DBA2 $(113 \pm 20 \mathrm{mg} / \mathrm{dL}$ and $304 \pm 49 \mathrm{mg} \cdot \mathrm{h} / \mathrm{dL}, P<.01)$, and BalbC mice $(174 \pm 55 \mathrm{mg} / \mathrm{dL}$ and $416 \pm 70 \mathrm{mg} \cdot \mathrm{h} / \mathrm{dL})$. Cardiac output was higher $($ all $P<.05)$ in Swiss $(14038 \pm 4530 \mu \mathrm{L} / \mathrm{min})$ versus C57BL/6J (10405 $\pm 2683 \mu \mathrm{L} / \mathrm{min})$, DBA2 $(10438 \pm 3251 \mu \mathrm{L} / \mathrm{min})$, and BalbC mice $(8466 \pm 3013 \mu \mathrm{L} / \mathrm{min})$. Load-independent left ventricular contractility assessed as recruitable stroke work (PRSW) was comparable in all strains. In conclusion, glucose tolerance and load-dependent left ventricular performance parameters were different between 4 mice background strains, but PRSW was comparable.
\end{abstract}

\section{Introduction}

Multiple transgenic mouse models have been and are being developed in cardiovascular research to study hypertension [1], diabetes [2], atherosclerosis [3], hypertrophic cardiomyopathy [4], heart failure [5], and many other diseases. These different experimental models are generated and studied in different mouse strains and genetic backgrounds.

Evaluating these disease models can be confounded not only by differences in gender [6] or environment [7] but also by baseline differences associated with their genetic background [8]. Obtaining the baseline characteristics of different background strains may therefore lead to a better understanding of cardiovascular research with laboratory animals. Reference values concerning left ventricular contractility parameters allow a more direct comparison and a correct interpretation of obtained results in specific studies.

We hypothesize that four frequently used mice strains (C57BL/6J, Swiss, BalbC, and DBA2 mice) exhibit a significantly different baseline left ventricular contractility and that glucose handling capacity is also different between these 4 strains. As glucose handling capacity could play an important role in the development of diabetes mellitus type 2 [9], hypertension [10], atherosclerosis [11], and heart failure [12], our findings could contribute to a better understanding of the decrease in left ventricular contractility that accompanies these pathological conditions. The C57BL/6J "black six" mouse is by far the most widely used mouse inbred strain. The strain is characterised by a high susceptibility to diet-induced obesity, with a moderate hyperglycemia and hyperinsulinemia $[13,14]$. Genetic differences in metabolic response to fat have been suggested to be more important in their development of obesity and diabetes than calory intake [15]. Furthermore, they appear highly susceptible to the development of atherosclerosis on a semisynthetic high-fat diet [16], although their plasma cholesterol levels at 12 and 24 weeks are rather low [17].

The Swiss mouse strain was originally selected in 1935 for its ease in breading. It is an albino mouse strain, used over 
all the branches of biomedical research, especially in cancer research [18], toxicity studies [19], and infective diseases [20].

The BalbC strain is used as a general purpose strain in many disciplines. They develop high plasma cholesterol levels [21] and high systolic blood pressures [22] but are resistant to diet-induced atherosclerosis [23]. Although their mean heart rate is rather low, they show a high heart rate adaptation [24]. BalbC mice show a high incidence of epicardial mineralisation ( $11 \%$ in males and $4 \%$ in females) which increases with age [25]. Overall heart defects, including cardiac calcinosis, occur frequently in about 17 $62 \%[26]$.

Finally the DBA2 strain is a widely used strain in cardiovascular, biological, and neurobiological research. Their susceptibility for developing atherosclerotic lesions is low and therefore are often contrasted with the C57BL/6 strain. The strain did not only show to be resistant to the development of atherosclerosis on a semisynthetic high fat diet [12] but also hyporesponsive to diets containing high levels of cholesterol and fat [27]. Spontaneous calcified heart lesions progressively develop with age, and at 1 year $90 \%$ of the mice are expected to be affected [28]. Brunnert suggested in 1997 [29] that dystrophic cardiac calcification may be related to a disturbed myocyte calcium metabolism.

Although it is thus clear that these 4 strains have different metabolic characteristics, with influence on cardiovascular disease development, no direct comparison of glucose tolerance has been published in these strains, nor was left ventricular contractility systematically compared. We therefore performed in vivo intraperitoneal glucose tolerance testing and cardiac pressure-conductance measurements in Swiss, C57BL/6J, DBA2, and BalbC mice at 24 weeks.

\section{Materials and Methods}

2.1. Animals. 19 C57BL/6J, 14 BalbC, 14 DBA2, and 18 Swiss mice were investigated. All animals were purchased form Jackson Laboratories (Bar Harbour, Maine, USA) and housed at $22^{\circ} \mathrm{C}$ on a fixed 12-hour light-dark cycle. The investigation conforms with the Guide for the Care and Use of Laboratory Animals published by the US National Institutes of Health (NIH Publication no. 85-23, revised 1996). All experimental protocols were approved by the Institutional Animal Care Commission and Ethical Committee of the K.U.Leuven.

2.2. Fasting IPGTT Testing. Intraperitoneal glucose tolerance testing was performed at 23 weeks with a bolus glucose injection of $2 \mathrm{mg} / \mathrm{g}$ body weight and followed by measuring the blood glucose levels at fixed timepoints (fasting and after $15,30,60,120$, and 240 minutes, resp.).

2.3. Left Ventricular Pressure-Conductance Measurements. At 24 weeks, mice were anesthetized with a mixture of urethane $(1.2 \mathrm{~g} / \mathrm{kg})$ and alpha-chloralose $(50 \mathrm{mg} / \mathrm{kg})$ injected intraperitoneally. Mice were placed on a heating pad, and rectal temperature was kept between 36.0 and $37.5^{\circ} \mathrm{C}$. Surgery was performed under a surgical microscope. Through a midline neck incision, a tracheostomy was performed, and mechanical ventilation started with room air (Minivent 845; Hugo Sachs/Harvard Apparatus, March-Hugstetten, Germany). Subsequently, a 1.4 Fr highfidelity pressure-conductance catheter (1.4-Fr, SPR-839; Millar Instruments, Houston, TX) was inserted through the right carotid artery into the left ventricle, and left ventricular pressure-conductance measurements were started. After stabilization of the hemodynamic situation, baseline pressure-volume (PV) loops were recorded (PowerLab/4SP ADInstruments, Castle Hill, Australia), while the ventilation was momentarily turned off to avoid respiratory fluctuation of cardiac signals. The inferior caval vein was compressed between liver and diaphragm with a cotton swab without opening the abdomen, while PV loops were recorded to obtain occlusion loops with progressively lowering preload. Afterwards a $24 \mathrm{G}$ catheter was introduced in the right jugular vein, and parallel volume was determined by a bolus injection of $3 \mu \mathrm{L}$ of $30 \%$ sodium chloride solution while recording PV loops. Following baseline measurements, an intravenous line was prepared with isoproterenol, and dose was increased gradually from 3, 9, 30 to finally $90 \mathrm{ng} / \mathrm{kg} / \mathrm{min}$. Dose-response curves of the load-dependent and loadindependent contractility parameters to isoproterenol infusion were obtained finally. A laparotomy was performed, and the inferior caval vein was exposed infrahepatically. With a $24 \mathrm{G}$ needle, $300 \mu \mathrm{L}$ of blood was retrieved from the inferior caval vein to measure specific conductivity in 3 precalibrated cuvettes.

2.4. Data Management and Statistical Analysis. Analysis after IPGTT testing included calculation of peak glucose levels and area under the curve. Peak glucose levels were obtained 30 minutes after bolus injection and expressed as $\mathrm{mg} / \mathrm{dL}$. Areas under the curve were calculated as the sum of the measured values, normalized for the time interval, and expressed in $\mathrm{mg} \cdot \mathrm{h} / \mathrm{dL}$.

Analysis of the pressure-conductance data was performed using PVAN 3.2 software (Millar Instruments, Houston, TX). A conductance-volume calibration line was constructed with the cuvette data. All data were corrected for parallel volume and expressed in absolute volumes. Only technically acceptable loops were included in the analysis for each experiment [30].

Data are expressed as mean \pm standard deviation. Significant changes were detected by single regression, and normality was assessed by the Shapiro-Wilk $W$ test. Baseline differences between groups were compared by breakdown one-way ANOVA, followed by an LSD post hoc test and a repeated measurements ANOVA when data was normally distributed. The nonparametric Mann-Whitney $U$ test and Wilcoxon Matched Pairs test was used when data was not normally distributed, and the Kruskal-Wallis ANOVA was used to compare survival between strains. Statistical software (Statistica 8 , StatSoft) was used. A value of $P<.05$ was considered significant. 
TABLE 1: Morphology in 4 mice background strains. All data are expressed as mean \pm standard deviation. Values marked with * are $P<.05$ versus all others.

\begin{tabular}{lcccc}
\hline & Swiss & C57BL6/J & DBA2 & BalbC \\
\hline Body weight (BW) (g) & $44.8 \pm 5.1^{*}$ & $26.1 \pm 4.6$ & $27.1 \pm 2.7$ & $27.0 \pm 2.8$ \\
Heart weight (g) & $0.19 \pm 0.03^{*}$ & $0.14 \pm 0.02$ & $0.14 \pm 0.02$ & $175 \pm 3$ \\
Tibial length (um) & $193 \pm 7^{*}$ & $185 \pm 7$ & $82.94 \pm 14.21$ & $174 \pm 4$ \\
HW/TL (g/100 um) & $99.36 \pm 16.08^{*}$ & $77.62 \pm 10.99$ & 5.01 & $79.64 \pm 8.66$ \\
HW/BW (mg/g) & $4.26 \pm 0.41^{*}$ & $5.51 \pm 0.31$ & & $5.13 \pm 0.31$ \\
\hline
\end{tabular}

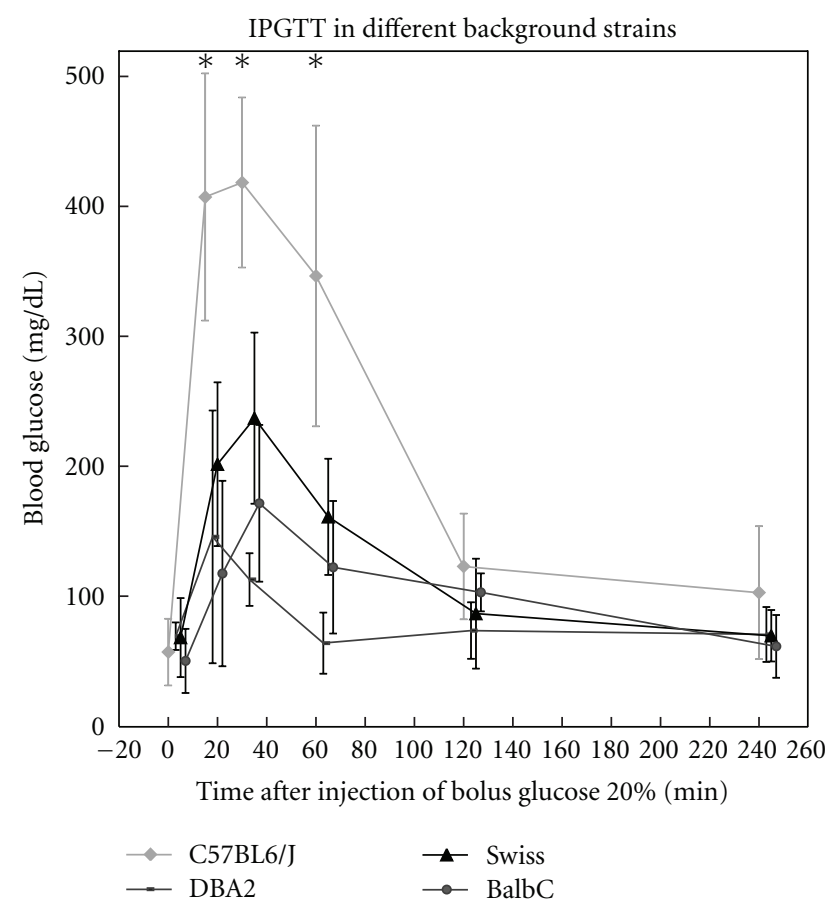

FIGURE 1: Intraperitoneal glucose tolerance testing in 4 background strains at 23 weeks. Lean values are similar between the studied groups. Values after 15, 30, and 60 minutes are significantly higher in C57BL/6J mice versus other strains. Values with $P<.01$ are marked with*.

\section{Results}

3.1. Mortality and Morphology. Between 12 and 24 weeks of age, 1 BalbC, 1 DBA2, and 2 Swiss mice died a sudden unexplained death. During the experimental procedure, 1 Swiss mouse and 2 BalbC mice died during the baseline pressureconductance measurements. Under increasing isoproterenol dose, in total, 4 Swiss, 6 C57BL/6J, 2 DBA2, and 7 BalbC mice died before $90 \mathrm{ng} / \mathrm{kg} / \mathrm{min}$ isoproterenol was reached. Survival during the experimental protocol was significantly lower in BalbC mice versus the other strains and occurred mainly during isoproterenol infusion $(P<.05)$.

Heart weight (HW), body weight (BW), tibial length (TL), and HW/TL were significantly higher in Swiss mice at 24 weeks versus all other strains $(P<.01$ for $\mathrm{HW}$ and BW, $P<.05$ for TL and HW/TL). Heart weight over body weight $(\mathrm{HW} / \mathrm{BW})$ was significantly lower in Swiss mice $(P<.001$, versus all); see Table 1.
3.2. IPGTT Testing. Fasting glucose levels at 24 weeks were comparable between the four studied strains. During intraperitoneal glucose tolerance testing, all mice showed a strong increase in blood glucose values (Figure 1). In C57BL/6J mice, the peak glucose level after 30 minutes (418 $65)$ was significantly higher than the Swiss $(237 \pm 66 \mathrm{mg} / \mathrm{dL}$, $P<.001)$, the DBA2 $(113 \pm 20 \mathrm{mg} / \mathrm{dL}, P<.001)$, and the BalbC group $(174 \pm 55 \mathrm{mg} / \mathrm{dL}, P<.001)$. AUC in C57BL/6J mice was $813 \pm 100 \mathrm{mg} \cdot \mathrm{h} / \mathrm{dL}$, and this was significantly higher than in the Swiss $(470 \pm 126 \mathrm{mg} \cdot \mathrm{h} / \mathrm{dL}, P<.01)$, the DBA2 $(304 \pm 49 \mathrm{mg} \cdot \mathrm{h} / \mathrm{dL}, P<.01)$, and the BalbC group $(416 \pm$ $70 \mathrm{mg} \cdot \mathrm{h} / \mathrm{dL}, P<.001)$.

3.3. Baseline Cardiac Performance (Table 2). At baseline, Swiss mice had the fastest heart rate $(P<.01$ versus all other strains). End-systolic pressure (Pes) was higher in BalbC mice versus the Swiss, DBA2, and C57BL/6J mice $(P<.05$ for all). End-systolic volume (Ves) was lower in Swiss and DBA2 mice versus $\mathrm{C} 57 \mathrm{BL} / 6 \mathrm{~J}$ and BalbC mice (both $P<.01$ ), while enddiastolic volume (Ved) was only significantly lower in DBA2 versus $\mathrm{C} 57 \mathrm{BL} / 6 \mathrm{~J}(P<.05)$. The maximal systolic pressure $\left(P_{\max }\right)$ was higher in Swiss versus C57BL/6J $(P<.05)$ but not versus DBA2 or BalbC. Ejection fraction (EF) was higher in DBA2 and Swiss mice versus C57BL/6J mice and BalbC mice (both $P<.001$ ), and stroke volume (SV) was higher in Swiss versus $\mathrm{C} 57 \mathrm{BL} / 6 \mathrm{~J}$ and BalbC mice $(P<.05)$ but not versus DBA2 mice $(P=.22)$.

Cardiac output (CO) and maximal rate of pressure development during isovolumetric contraction $\left(\mathrm{d} P \mathrm{~d} t_{\max }\right)$ were higher in Swiss versus C57BL/6J $(P<.01$ and $P<.001)$, DBA2 $(P<.01$ and $P<0.05)$, and BalbC mice (both $P<.001)$. Tau was higher in BalbC and C57BL/6J mice versus Swiss and DBA2 mice (both $P<.05$ ), but the maximal rate of pressure decay $\left(\mathrm{d} P \mathrm{~d} t_{\min }\right)$ was comparable between the studied strains. Arterial elastance (Ea) was significantly higher in BalbC mice versus other strains (all $P<.05$ ).

The load-independent preload recruitable stroke work (PRSW) and the end-systolic elastance (Ees) were not significantly different between the four studied groups $(P>.05)$. The slope of the end-diastolic pressure-volume relationship (slope EDPVR) was higher in BalbC mice $(P<.05)$, but the parameter of mechanical efficiency of the left ventricle (stroke work to PV area (PVA) ratio, SW/PVA) was lower in BalbC mice versus the other groups $(P<.05)$.

3.4. Changes in Cardiac Performance under Increasing Isoproterenol Infusion (See Table 3 and Figure 2). All species 
TABle 2: Pressure-conductance analysis in 4 mice background strains. All data are expressed as mean \pm standard deviation. Values marked with ${ }^{\psi}$ are $P<.05$ versus ${ }^{\triangle}$ and values marked with ${ }^{*}$ are $P<.05$ versus all others.

\begin{tabular}{|c|c|c|c|c|}
\hline Heart rate (bpm) & $623 \pm 71^{*}$ & $569 \pm 43$ & $545 \pm 40$ & $566 \pm 35$ \\
\hline Ves $(\mathrm{uL})$ & $10.9 \pm 5.1^{\psi}$ & $16.5 \pm 6.2^{\Delta}$ & $9.0 \pm 3.1^{\psi}$ & $18.0 \pm 4.6^{\Delta}$ \\
\hline Ved (uL) & $30.7 \pm 9.1$ & $31.8 \pm 7.2^{\psi}$ & $25.8 \pm 7.1^{\triangle}$ & $30.0 \pm 9.9$ \\
\hline Pes $(\mathrm{mmHg})$ & $69.5 \pm 9.9$ & $76.8 \pm 8.2$ & $71.9 \pm 8.0$ & $84.2 \pm 13.6^{*}$ \\
\hline Ped (mmHg) & $1.2 \pm 1.7$ & $1.9 \pm 2.0$ & $1.2 \pm 1.2$ & $2.9 \pm 2.9$ \\
\hline$P_{\max }(\mathrm{mmHg})$ & $90 \pm 5^{\psi}$ & $84 \pm 6^{\Delta}$ & $88 \pm 7$ & $89 \pm 11$ \\
\hline $\mathrm{EF}(\%)$ & $70.4 \pm 11.2^{\triangle}$ & $55.9 \pm 13.4^{\psi}$ & $71.8 \pm 9.2^{\triangle}$ & $47.8 \pm 5.7^{\psi}$ \\
\hline Cardiac output (uL/min) & $14038 \pm 4530^{*}$ & $10405 \pm 2683$ & $10438 \pm 3251$ & $8466 \pm 3013$ \\
\hline $\mathrm{d} P / \mathrm{d} t_{\max }(\mathrm{mmHg} / \mathrm{s})$ & $11746 \pm 2105^{*}$ & $7162 \pm 1563$ & $9420 \pm 2268$ & $7760 \pm 1581$ \\
\hline $\mathrm{d} P / \mathrm{d} t_{\min }(\mathrm{mmHg} / \mathrm{s})$ & $-7738 \pm 2098$ & $-7948 \pm 1242$ & $-8204 \pm 1458$ & $-8547 \pm 1464$ \\
\hline Tau & $4.1 \pm 0.7^{\psi}$ & $5.2 \pm 0.9^{\Delta}$ & $4.5 \pm 0.7^{\psi}$ & $5.2 \pm 0.8^{\triangle}$ \\
\hline Arterial elastance $(\mathrm{Ea})(\mathrm{mmHg} / \mu \mathrm{L})$ & $3.4 \pm 1.2$ & $4.4 \pm 1.2$ & $4.1 \pm 1.1$ & $6.2 \pm 1.9^{*}$ \\
\hline Ees & $9.5 \pm 5.0$ & $6.1 \pm 2.1$ & $8.4 \pm 3.8$ & $8.2 \pm 2.9$ \\
\hline $\operatorname{EDPVR}(\mathrm{mmHg} / \mu \mathrm{L})$ & $0.265 \pm 0.082$ & $0.218 \pm 0.074$ & $0.316 \pm 0.079$ & $0.415 \pm 0.159^{*}$ \\
\hline Preload recruitable stroke work (PRSW) (mmHg) & $92 \pm 22$ & $88 \pm 21$ & $94 \pm 25$ & $82 \pm 23$ \\
\hline Efficiency (SW/PVA) & $0.78 \pm 0.054$ & $0.70 \pm 0.08$ & $0.70 \pm 0.13$ & $0.60 \pm 0.11^{*}$ \\
\hline
\end{tabular}

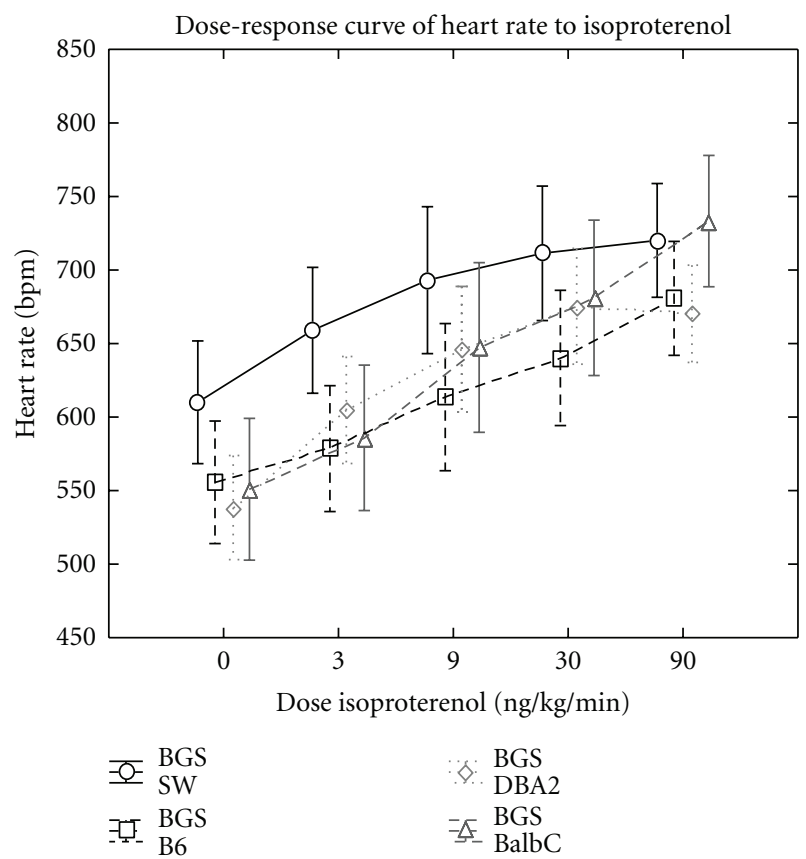

FIGURE 2: Illustration of the increase in heart rate under isoproterenol infusion in the four studied mice background strains.

showed an increase in $H R$ during isoproterenol infusion (Figure 2), but the HR increase was significantly larger in BalbC versus Swiss mice $(P<.05)$ (mean increase of $34 \pm 12 \%$ in BalbC mice versus $19 \pm 12 \%$ in Swiss, $23 \pm 9 \%$ in C57BL/6J, and $25 \pm 11 \%$ in DBA2 mice).

Under isoproterenol, Pes, Ped, and Ved decreased in all strains $(P<.05)$. Ejection fraction increased in C57BL/6J, DBA2, and BalbC mice $(P<.05)$ and tended to increase in Swiss mice $(P=.06)$. All species show a progressive decrease in tau under increasing isoproterenol dose (all $P<.05$ ). End-systolic elastance (Ees) increased significantly under isoproterenol in DBA2 and BalbC mice between 0 and $90 \mathrm{ng} / \mathrm{kg} / \mathrm{min}(P<.05)$. There were no significant changes in Ees in the Swiss or C57BL/6J group. However, the increase in PRSW only reached statistical significance in the BalbC group and not in the DBA2 mice.

\section{Discussion}

This study shows that left ventricular contractility and glucose handling capacity are significantly different in four mice background strains frequently used in cardiovascular research. Overall survival under isoproterenol infusion with invasive left ventricular contractility measurements was different between the studied strains.

4.1. Heart Weight. Body weight, heart weight, and left ventricular weight are significantly higher in Swiss versus the other studied strains. Although Swiss mice are at 24 weeks heavier than the other background strains, tibial length did not show an increase to the same extent as the heart weight increase, and this results in a higher HW/TL. In contrast, $\mathrm{HW} / \mathrm{BW}$ was lower in Swiss mice, because BW increase was more pronounced than the HW increase. HW over body surface area did not show significant differences between the 4 groups. When LV hypertrophy is studied, it is probably more safe to report HW/TL, HW/BW, and HW/BSA simultaneously.

4.2. IPGTT Testing. IPGTT in C57BL67/J showed higher peak glucose levels and a higher AUC versus the other strains. This suggests that capacity for glucose handling at 24 weeks is lower in C57BL/6J, although fasting glucose levels are not increased. These findings are in accordance with the findings of Gerich [9] and Vardeny et al. [12], and it is therefore beneficial to perform IPGTT testing, especially when transgenic models against a C57BL/6J mice background are studied. 


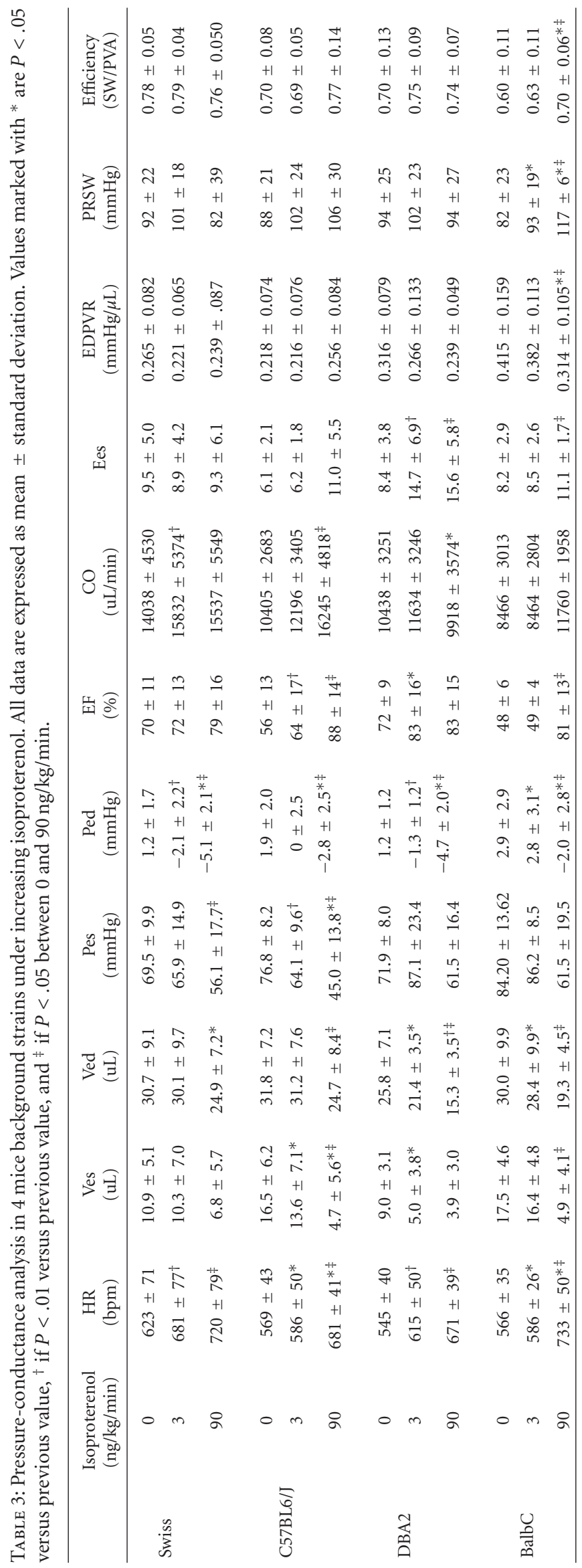


4.3. Baseline Cardiac Performance. Swiss mice exhibited a higher heart rate than the other strains, despite their higher body weight. An increased cardiac output to meet the metabolic demands of a larger individual is thus obtained by a combination of a higher resting $\mathrm{HR}$ and a relatively high SV.

Arterial elastance (Ea), a parameter for afterload, was higher in BalbC mice. Afterload is influenced by peripheral vascular resistance, arterial compliance, aortic characteristic impedance, and systolic and diastolic time intervals, and therefore any increase in afterload results in a decreased stroke volume, unless contractility is increased. The higher Ea can partially be explained by the higher systolic blood pressures described in BalbC mice (Schlager and sides [1]), and this is in accordance with the higher Pes that we found in both BalbC and especially C57BL/6J mice versus Swiss and DBA2 mice.

$\mathrm{d} P / \mathrm{d} t_{\max }$ is dependent on preload, Ved, and Ped. Differences in $\mathrm{d} P / \mathrm{d} t_{\max }$ are useful to assess directional changes in inotropic state, but changes in preload are to be evaluated simultaneously. We found a significantly higher $\mathrm{d} P / \mathrm{d} t_{\max }$ in the Swiss mice, but, because heart rate was also higher in Swiss mice, load-independent contractility parameters should be assessed in order to compare LV contractility safely. PRSW was not different between the 4 studied strains. The relatively high slope EDPVR in BalbC mice together with the higher Tau suggest a reduced compliance of the ventricular wall in BalbC mice. Epicardial mineralisation or cardiac calcinosis, that are frequently found in this strain $[22,23]$, could contribute to these functional changes. SW/PVA was lowest in the BalbC group, indicating that their contractile efficiency is relatively low.

4.4. Changes under Isoproterenol. Isoproterenol affects the $\beta_{2}$ receptors of skeletal muscle arterioles, inducing vasodilatation, and interacts with the cardiac $\beta_{1}$ receptors, potentially leading to a positive inotropic and chronotropic effect. We observed a decrease in both Ped and Pes in all strains and a strong chronotropic increase under isoproterenol administration. The increase in HR was greater in BalbC mice than in Swiss mice, and the decrease in slope EDPVR was more pronounced in BalbC mice versus C57BL/6 mice. Ees increased in both the DBA2 and the BalbC group but was accompanied by a remarkable change of the PV loop shape with asymmetric and highly peaking pressure-volume loops. PRSW, a more robust parameter of LV contractility [31], did only increase in the BalbC group.

These findings suggest that the cardiac $\beta_{1}$ effect in these mice strains leads mainly to a chronotropic increase, although isoproterenol infusion in BalbC mice results in an increase in external work and efficiency for an increased preload, as shown by the increasing PRSW in the higher doses.

Glucose handling capacity was clearly reduced in C57BL/6J mice at 24 weeks. Although cardiac performance parameters were significantly different between the four studied strains, C57BL/6J mice did not show a difference in cardiac performance. Thus, the contractility changes that have been reported for experimental mice models of diabetes mellitus type 2 do not seem to precede the diabetic state. Most likely, pronounced and sustained hyperglycemia is required to clearly influence cardiac performance parameters.

\section{Conclusion}

Swiss mice were significantly larger at 24 weeks with inconsistent cardiac hypertrophy parameters. Glucose handling capacity was reduced in C57BL/6J mice, but this did not lead to a pronounced difference in cardiac performance. Survival under increasing isoproterenol dose was significantly lower in the BalbC mice. Although baseline cardiac performance was different between the 4 studied strains, the loadindependent PRSW was comparable.

\section{Acknowledgments}

Wouter Oosterlinck received a Ph.D. fellowship of the Research Foundation-Flanders (FWO). This work was supported by a research grant of the Research Fund K.U.Leuven, PF/10/014, and a grant of the Scientific Research FundFlanders (F.W.O.-Vlaanderen G.0966.11).

\section{References}

[1] G. Schlager and J. Sides, "Characterization of hypertensive and hypotensive inbred strains of mice," Laboratory Animal Science, vol. 47, no. 3, pp. 288-292, 1997.

[2] J. Mayer, M. W. Bates, and M. M. Dickie, "Hereditary diabetes in genetically obese mice," Science, vol. 113, no. 2948, pp. 746747, 1951.

[3] S. Ishibashi, J. L. Goldstein, M. S. Brown, J. Herz, and D. K. Burns, "Massive xanthomatosis and atherosclerosis in cholesterol-fed low density lipoprotein receptor-negative mice," Journal of Clinical Investigation, vol. 93, no. 5, pp. 18851893, 1994.

[4] T. Tsoutsman, M. Kelly, D. C. H. Ng et al., "Severe heart failure and early mortality in a double-mutation mouse model of familial hypertrophic cardiomyopathy," Circulation, vol. 117, no. 14, pp. 1820-1831, 2008.

[5] K. Kuwahara, Y. Saito, M. Takano et al., "NRSF regulates the fetal cardiac gene program and maintains normal cardiac structure and function," EMBO Journal, vol. 22, no. 23, pp. 6310-6321, 2003.

[6] K. M. Shioura, D. L. Geenen, and P. H. Goldspink, "Sex-related changes in cardiac function following myocardial infarction in mice," American Journal of Physiology, vol. 295, no. 2, pp. R528-R534, 2008.

[7] B. S. Knight, N. Sunn, C. E. Pennell, S. L. Adamson, and S. J. Lye, "Developmental regulation of cardiovascular function is dependent on both genotype and environment," American Journal of Physiology, vol. 297, no. 6, pp. H2234-H2241, 2009.

[8] M. J. Campen, Y. Tagaito, J. Li et al., "Phenotypic variation in cardiovascular responses to acute hypoxic and hypercapnic exposure in mice," Physiological Genomics, vol. 20, pp. 15-20, 2005. 
[9] J. E. Gerich, "Role of the kidney in normal glucose homeostasis and in the hyperglycaemia of diabetes mellitus: therapeutic implications," Diabetic Medicine, vol. 27, no. 2, pp. 136-142, 2010.

[10] L. M. Resnick, "Ionic basis of hypertension, insulin resistance, vascular disease, and related disorders. The mechanism of 'syndrome X', American Journal of Hypertension, vol. 6, no. 4, pp. S123-S134, 1993.

[11] F. Khan, H. Kerr, R. A. Ross, D. J. Newton, and J. J. Belch, "Effects of poor glucose handling on arterial stiffness and left ventricular mass in normal children," International Angiology, vol. 25, no. 3, pp. 268-273, 2006.

[12] O. Vardeny, M. A. Detry, J. J. M. Moran, M. R. Johnson, and N. K. Sweitzer, "The $\beta$ adrenergic receptor GIn27Glu polymorphism affects insulin resistance in patients with heart failure: possible modulation by choice of beta blocker," Journal of Cardiovascular Pharmacology, vol. 52, no. 6, pp. 500-506, 2008.

[13] R. S. Surwit, C. M. Kuhn, C. Cochrane, J. A. McCubbin, and M. N. Feinglos, "Diet-induced type II diabetes in C57BL/6J mice," Diabetes, vol. 37, no. 9, pp. 1163-1167, 1988.

[14] R. S. Surwit, M. F. Seldin, C. M. Kuhn, C. Cochrane, and M. N. Feinglos, "Control of expression of insulin resistance and hyperglycemia by different genetic factors in diabetic C57BL/6J mice," Diabetes, vol. 40, no. 1, pp. 82-87, 1991.

[15] R. S. Surwit, M. N. Feinglos, J. Rodin et al., "Differential effects of fat and sucrose on the development of obesity and diabetes in C57BL/6J and A/J mice," Metabolism, vol. 44, no. 5, pp. 645651, 1995.

[16] P. M. Nishina, J. Wang, W. Toyofuku, F. A. Kuypers, B. Y. Ishida, and B. Paigen, "Atherosclerosis and plasma and liver lipids in nine inbred strains of mice," Lipids, vol. 28, no. 7, pp. 599-605, 1993.

[17] R. S. Weibust, "Inheritance of plasma cholesterol levels in mice," Genetics, vol. 73, no. 2, pp. 303-312, 1973.

[18] A. Nyska, T. Waner, H. Tal, and D. Dayan, "Spontaneous ameloblastic fibro-odontoma in a female mouse," Journal of Oral Pathology and Medicine, vol. 20, no. 5, pp. 250-252, 1991.

[19] J. L. Domingo, J. L. Paternain, J. M. Llobet, and J. Corbella, "The developmental toxicity of uranium in mice," Toxicology, vol. 55, no. 1-2, pp. 143-152, 1989.

[20] S. L. Abbott, R. P. Kokka, and J. M. Janda, "Laboratory investigations on the low pathogenic potential of Plesiomonas shigelloides," Journal of Clinical Microbiology, vol. 29, no. 1, pp. 148-153, 1991.

[21] R. A. K. Srivastava, S. Jiao, J. Tang, B. A. Pfleger, R. T. Kitchens, and G. Schonfeld, "In vivo regulation of low-density lipoprotein receptor and apolipoprotein B gene expression by dietary fat and cholesterol in inbred strains of mice," Biochimica et Biophysica Acta, vol. 1086, no. 1, pp. 29-43, 1991.

[22] G. Schlager and R. S. Weibust, "Genetic control of blood pressure in mice," Genetics, vol. 55, no. 3, pp. 497-506, 1967.

[23] B. Paigen, D. Mitchell, P. A. Holmes, and D. Albee, "Genetic analysis of strains $\mathrm{C} 57 \mathrm{BL} / 6 \mathrm{~J}$ and $\mathrm{BALB} / \mathrm{cJ}$ for Ath-1, a gene determining atherosclerosis susceptibility in mice," Biochemical Genetics, vol. 25, no. 11-12, pp. 881-892, 1987.

[24] D. Blizard and R. Welty, "A technique for monitoring the heart rate of mice," Psychophysiology, vol. 7, no. 1, pp. 143-144, 1970.

[25] C. H. Frith, T. J. Haley, and B. W. Seymore, "Spontaneous epicardial mineralization in BALB/cStCrl mice," Laboratory Animal Science, vol. 25, no. 6, p. 787, 1975.
[26] M. F. Festing and D. K. Blackmore, "Life span of specifiedpathogen-free (MRC category 4) mice and rats," Laboratory Animals, vol. 5, no. 2, pp. 179-192, 1971.

[27] R. C. LeBoeuf and E. A. Kirk, "Dietary regulation of plasma lipid concentrations in the mouse," in Proceedings of the Conference on Nutrition, Genetics, and Heart Disease, pp. 316330, Baton Rouge, La, USA, March 1995.

[28] R. W. Rings and J. E. Wagner, "Incidence of cardiac and other soft tissue mineralized lesions in DNA-2 mice," Laboratory animal science, vol. 22, no. 3, pp. 344-352, 1972.

[29] S. R. Brunnert, "Morphologic response of myocardium to freeze-thaw injury in mouse strains with dystrophic cardiac calcification," Laboratory Animal Science, vol. 47, no. 1, pp. 1118, 1997.

[30] A. Van Den Bergh, A. Vanderper, P. Vangheluwe et al., "Dyslipidaemia in type II diabetic mice does not aggravate contractile impairment but increases ventricular stiffness," Cardiovascular Research, vol. 77, no. 2, pp. 371-379, 2008.

[31] A. Van Den Bergh, W. Flameng, and P. Herijgers, "Parameters of ventricular contractility in mice: influence of load and sensitivity to changes in inotropic state," Pflugers Archiv European Journal of Physiology, vol. 455, no. 6, pp. 987-994, 2008. 


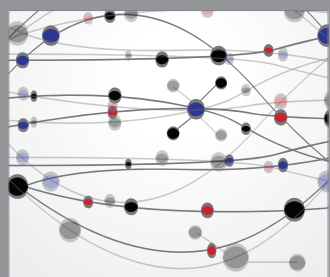

The Scientific World Journal
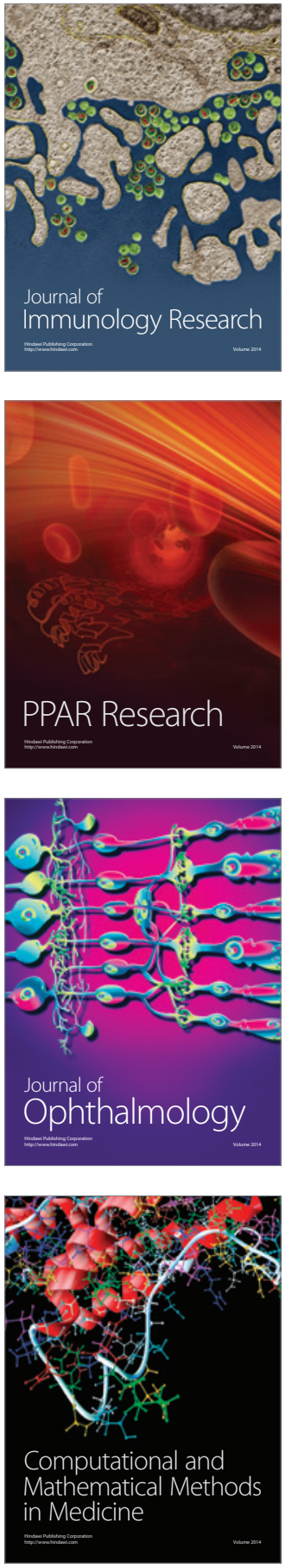

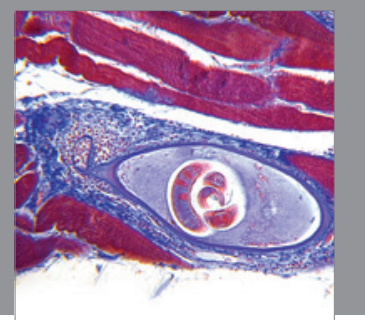

Gastroenterology

Research and Practice
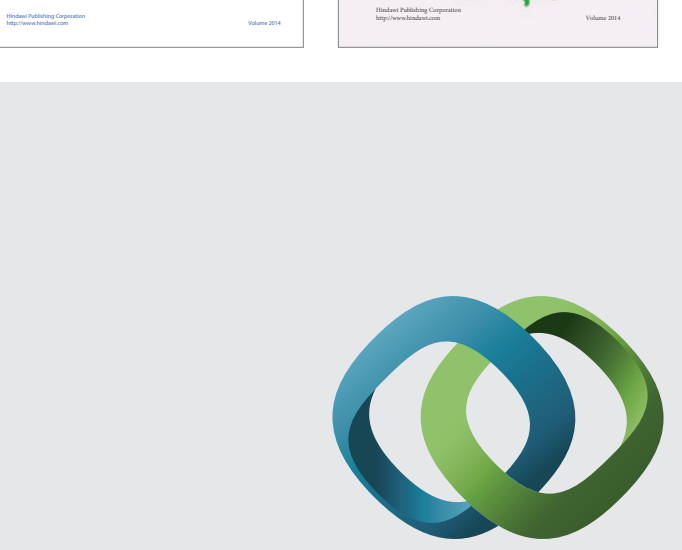

\section{Hindawi}

Submit your manuscripts at

http://www.hindawi.com
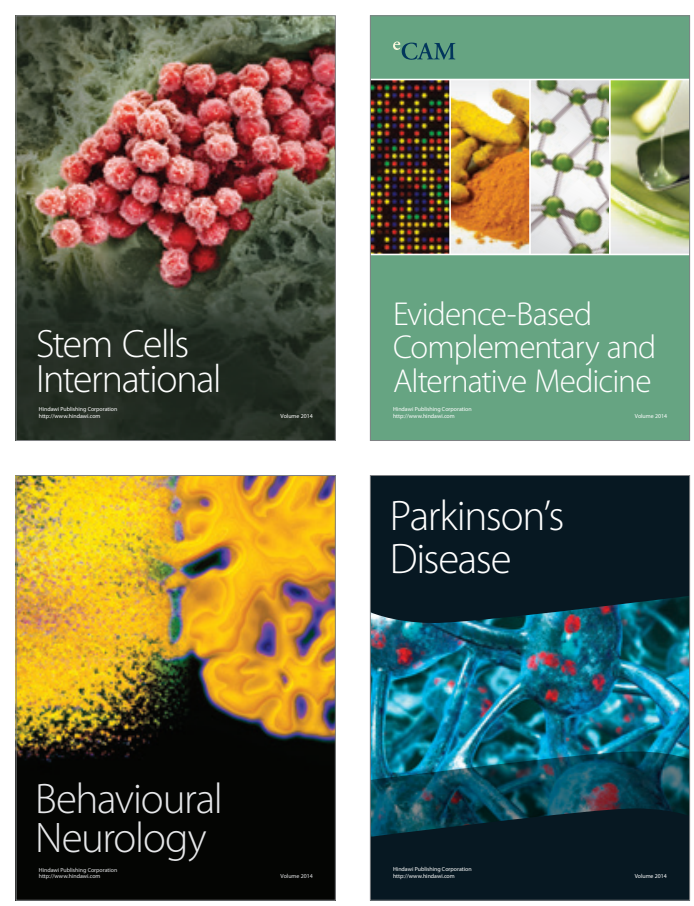

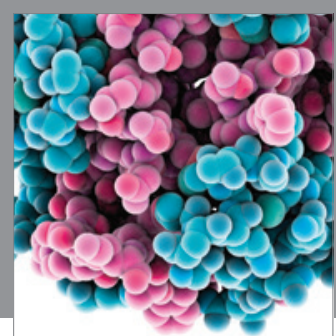

Journal of
Diabetes Research

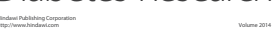

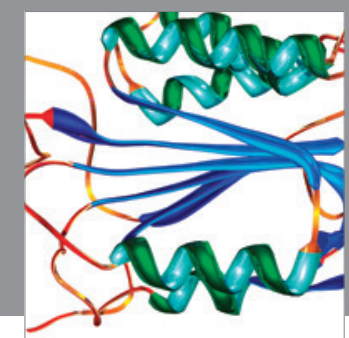

Disease Markers
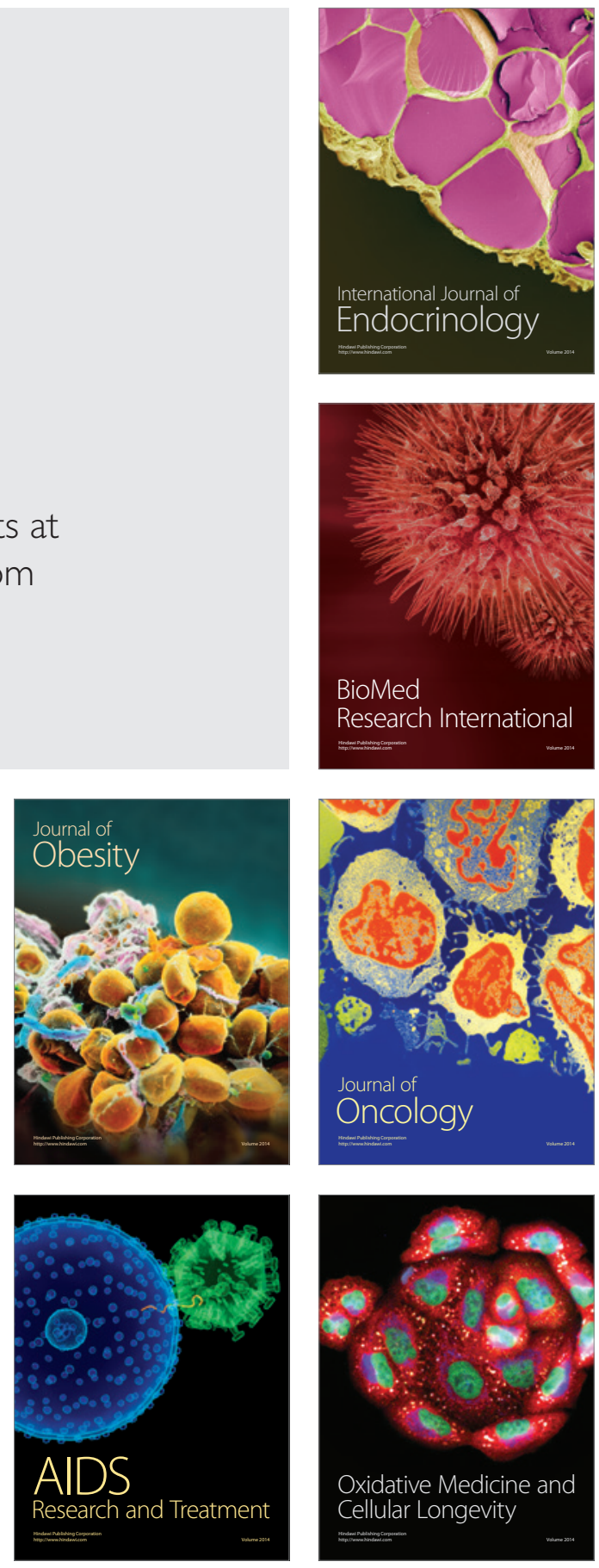